ISSN 1991-8631

Original paper

http://indexmedicus.afro.who.int

\title{
Effects of food flavour enhancer (Monosodium Glutamate and Maggi Poulet) supplementation on glucose tolerance in Sprague Dawley rat
}

\author{
Maclewè N. TCHAOU ${ }^{1}$, Courdjo LAMBONI ${ }^{1 *}$, Kwashie EKLU-GADEGBEKU ${ }^{2}$, \\ Esso-yabam ABALOKOKA ${ }^{1}$ and Kodjo A. AKLIKOKOU ${ }^{2}$ \\ ${ }^{1}$ Laboratoire de Biochimie/Nutrition, Faculté des Sciences, Université de Lomé, Togo. \\ ${ }^{2}$ Laboratoire de Physiologie-Pharmacologie, Faculté des Sciences, Université de Lomé, BP: 1515 Lomé, Togo. \\ *Corresponding author; E-mail: racoulamboni@gmail.com; Tel.0022890032990.
}

\begin{abstract}
This study was designed to evaluate the effects of purified monosodium glutamate and 'Maggi Poulet', on body weight gain, lipid profile, hepatic lipid peroxidation and glucose tolerance in rats. Thirty five young male Sprague Dawley rats were divided into five groups and fed by oral route as follow: group I (distilled water), group II (monosodium glutamate solution), group III ('Maggi Poulet'solution), group IV (monosodium glutamate solution. and high fat solution) and group V ('Maggi Poulet' solution and high fat solution). During the experimental period, fasting glycemia was taken and an oral glucose tolerance test has been performed at the end. Blood samples were then collected in all groups and serum cholesterol and triglyceride were assayed. Animals were killed after and abdominal adipose tissue, liver and heart were excised and weighed. Liver samples were also used to estimate hepatic malondialdehyde level in rats. The results proved that the dietary feeding did not affect the body gain and lipid profile in experimental groups. The hepatic lipid peroxidation has also increased in all experimental groups and at the same time, rats in group II, group IV and group V present a two-hour plasma glucose level signifantly higher. However, purified monosodium glutamate and 'Maggi Poulet' at the dose of $1500 \mathrm{mg} / \mathrm{kg}$. b. wt. have not impaired fasting glycemia in Sprague Dawley rat. All changes observed in the glycemia of rats in experimental groups do not allow to qualify them to be glucose intolerant, nevertheless monosodium glutamate consumption in association or not with high fat is hepatotoxic and may contribute to the emergence of prediabetes in human being.
\end{abstract}

(c) 2013 International Formulae Group. All rights reserved.

Keywords: Malondialdehyde, lipid profile, glucose homeostasis, prediabetes.

\section{INTRODUCTION}

Impaired glucose tolerance (IGT) and impaired fasting glucose (IFG) are intermediate states of abnormal glucose regulation that exist between normal glucose homeostasis and diabetes (David et al., 2007). These two features of glucose intolerance differ in their site of insulin resistance. IFG is associated with hepatic insulin resistance whereas IGT manifest itself by muscle insulin resistance (Brohall et al., 2006). According to the recommendations of the American Diabetes Association; IFG is defined for fasting plasma glucose level in the range of 100 to $125 \mathrm{mg} / \mathrm{dl}$ and a two-hour plasma glucose level less than $140 \mathrm{mg} / \mathrm{dl}$ and IGT is 
characterised by a fasting plasma glucose less $100 \mathrm{mg} / \mathrm{dl}$, a two-hour plasma glucose level going from 140 to $199 \mathrm{mg} / \mathrm{dl}$ and the glycated haemoglobin $\mathrm{A}_{1 \mathrm{c}}$ rate included between 5.7\% to $6.4 \%$ (Buysschaert and Bergam, 2011).

It is generally agreed that genetic background, dietary habits and physical inactivity may contribute to the pathogenesis of these disorders. In order to improve the understanding of the mechanisms involved in the onset of insulin resistance and obesity; various rodent models have been developped. Based upon genetic susceptibility, there are close to 50 different types of genetic models of obesity in rodents among which, obese mice (ob/ob, db/db) and Zucker rats (fa/fa) are used as sample animals of diabetes in biological and medical studies (Von Diemen et al., 2006). There are also diabetic rodent models obtained through chemical induction using gold-thioglucose, alloxan or streptozocin (Huang et al., 2004) and experimental ablation of the pancreas or the arcuate nucleus (Von Diemen et al., 2006).

However, those previous models do not sufficiently manifest prediabetic state when we need to extrapolate results from rodent to human being. Dietary rodent models are therefore proposed and several substances such as high fat, trans-fat, sucrose, fructose and recently monosodium glutamate (MSG) have been proposed (Diniz et al., 2004; Collison et al., 2010, Singh et al., 2011). In most cases, MSG subcutaneous injections or large oral dose of MSG dietary supplementation in rodent have shown an impairment of glucose homeostasis, a dyslipidemia and weight gain (Hermanussen et al., 2006).

In contrast to previous studies, Boutry et al. (2011) have reported that 2\% MSG diet chronic supplementation had no effect on food intake, body weight, and adipose tissue mass in Wistar rat. Furthermore, Kondoh and Torii (2008) reported that $1 \%$ MSG dissolved in the drinking water was able to reduce weight gain, body fat mass, and plasma leptin concentrations in Sprague Dawley rats. The mechanism underlying MSG-induced obesity and insulin resistance in non physiological situation remains unclear and controversial (Boutry et al., 2011).

The use of bouillon cube containing MSG in spite of purified MSG in household preparation of food is very popular in SubSaharan African countries (Sop et al., 2008; Akpamu et al., 2011). 'Maggi Poulet' (MP) is one of the most commonly cube-type seasoning added to soups in Lomé (Togo). Sop et al. (2008) have estimated the average free MSG content of MP to $13.5 \%$ (wt./wt.). The aim of this study is to investigate the effect of dietary MSG and MP with or without high fat supplementation on weight gain, lipid profile, hepatic lipid peroxidation and glucose tolerance in Sprague Dawley rat.

\section{MATERIALS AND METHODS \\ Chemicals}

Lard, MSG (West African Seasoning Company Limited, Lagos Nigeria) and MP (Nestlé Company, Dakar Senegal) were purchased from 'Gbonsimé' market, Lomé (Togo). Other chemicals such as thiobarbituric acid, phosphoric acid and cholesterol were from Sigma-Aldarich, France. Elitech/Biolabo kits, France, were used for estimation of total cholesterol, HDL cholesterol and triglycerides.
Animals
Male Sprague Dawley $(\mathrm{n}=35)$ strain weighing about $160 \mathrm{~g}$ were used for the experiments. The animals were provided by Nogoshi Medical Institute (University of Legon, Ghana). They were kept on a 12:12-h light-darkness cycle at the Animal House of the University of Lomé (Togo). They had free access to the standard diet and water $a d$ libitum. All animals were acclimated for 2 weeks before starting dietary feeding. 


\section{Experimental protocol}

The rats were divided into five groups of seven animals each and treated as follow: -Group I (control): the rats received distilled water $(5 \mathrm{ml} / \mathrm{kg} \mathrm{b}$. wt.) and thirty minutes after another dose of $10 \mathrm{ml} / \mathrm{kg} \mathrm{b}$. wt of the same distilled water

-Group II (MSG): the rats received monosodium glutamate aqueous solution $(1500 \mathrm{mg} / \mathrm{kg} \mathrm{b}$. wt.) and thirty minutes after another dose of $10 \mathrm{ml} / \mathrm{kg} \mathrm{b}$. wt of the distilled water

-Group III (MP): the rats received 'Maggi Poulet' aqueous solution (1500 mg/kg b. wt.) and thirty minutes after another dose of 10 $\mathrm{ml} / \mathrm{kg}$ b. wt. of the distilled water

-Group IV (MSG-HF): the rats received monosodium glutamate aqueous solution $(1500 \mathrm{mg} / \mathrm{kg} \mathrm{b}$. wt.) and thirty minutes after another dose of $10 \mathrm{ml} / \mathrm{kg} \mathrm{b}$. wt. of high fat solution

-Group V (MP-HF): the rats received 'Maggi Poulet' aqueous solution (1500 mg/kg b. wt.) and thirty minutes after another dose of 10 $\mathrm{ml} / \mathrm{kg} \mathrm{b}$. wt. of high fat solution.

Hight fat solution was prepared by dissolving $400 \mathrm{mg}$ of cholesterol in $10 \mathrm{ml}$ of melted lard. The total treatment period was sixty days and substance administration daily lasted one hour (9:00 a. m-10:00 a. m).

During the experimentation animals' body weight were measured daily while fasting glycemia was taken the first day and two weeks later using One Touch Ultra 2 glucometer. At the end of the treatment (60 days), all the rats were fasted overnight (12-14 h) for the oral glucose test tolerance (OGTT). Eighty per cent glucose aqueous solution was orally administered by gastric tube at the dose of $4 \mathrm{~g} / \mathrm{kg}$ b. wt per rat. Blood glucose rates were measured at tail vein before glucose administration and at 30,60, 120 min after the glucose administration. After the OGTT, blood samples were collected with a capillary tube from retro-orbital plexus of rat under ether anaesthesia. The collected blood was incubated at $37{ }^{\circ} \mathrm{C}$ until clotted and then, it was centrifuged to separate the serum. The serum samples were frozen to be used for measurement of total cholesterol (TC), HDL cholesterol (HDL-chol) and triglyceride (TG). Animals were killed by cervical decapitation and the abdominal cavity was opened. Liver, heart and intra-abdominal adipose tissue were dissected and weighed. Liver samples were frozen during 48 hours and hepatic lipid peroxidation was estimated by quantification of malondialdhehyde thiobarbituric acid adduct (MDA-TBA). Briefly, liver samples $(150 \mathrm{mg})$ were homogenised with cold $1.5 \%$ $\mathrm{KCl}$ in order to make $10 \%$ homogenate. Three millimetres of phosphoric acid and $1 \mathrm{ml}$ of $0.6 \%$ thiobarbituric acid aqueous solution were added to $0.5 \mathrm{ml}$ of the homogenate. The mixture was heated for $45 \mathrm{~min}$. After cooling, $4 \mathrm{ml}$ of $\mathrm{n}$-butanol was added to the homogenate and mixed. Absorbance of butanol phase was measured at 535 and 520 $\mathrm{nm}$. The difference of the two measurements was used as MDA concentration expressed in $\mathrm{nmol} / \mathrm{g}$ tissue (Sepici-Dincel et al., 2007; Bakoma et al., 2011)

\section{Data analysis}

All results were analysed using Graph Pad Prism 4.5 and expressed as mean \pm S.E.M. The significance of the difference between each group was determined by one way analysis of variance followed by Turkey post-hoc test $(\mathrm{p}<0.05)$.

\section{RESULTS}

As shown in Table 1, the final body weight, the body weight gain and the relative heart weight did not differ into the groups. Relative intra-abdominal fat deposition (mesenteric, retroperitoneal and epididymal fat) and relative liver weight were markedly higher in MSG-HF and MP-HF treated groups compared to the control group.

Overnight fasting glucose was not influenced neither by controlled diet nor MSG and MP ingestion. However, mean fasting glucose in MSG-HF and MP-HF groups had 
significantly increased from $15^{\text {th }}$ day onward till the end of the experimental period (Table 2). The OGTT showed that there were no differences in glucose rate after loading in controlled and MP groups. Otherwise, the glucose level after loading in MSG-HF group peaked and was the highest among all groups during the test (Table 3). At 120 min postglucose challenge, glucose concentrations were significantly higher in MSG, MSG-HF and MP-HF rats groups compared to the control $(\mathrm{p}<0.05)$. All rats in experimental groups tended to have elevated glucose area under curve (AUC) during the OGTT compared to the control; nevertheless only MSG-HF rats presented a glucose AUC significantly higher $(+23 \%$ versus control group).

In addition, there were no differences in total cholesterol, HDL cholesterol, LDL cholesterol, triglyceride into the five groups after dietary feeding (Table 4). Liver tissue MDA levels in contrast were significantly increased in all experimental groups compared to the control group $(\mathrm{p}<0.05)$.

Table 1: Effect of diets on body weight, and relative tissue weight after 60 days supplementation.

\begin{tabular}{|c|c|c|c|c|c|}
\hline \multirow[t]{2}{*}{ Parameters } & \multicolumn{5}{|c|}{ Groups } \\
\hline & Control & MSG & MP & MSG-HF & MP-HF \\
\hline Initial body weight (g) & $171.8 \pm 3.16$ & $169.71 \pm 2.86$ & $169.57 \pm 4.79$ & $170.66 \pm 3.6$ & $169 \pm 3.17$ \\
\hline Body weight gain $(\mathrm{g})$ & $102.4 \pm 5.65$ & $128.71 \pm 7.66$ & $101.57 \pm 2.82$ & $105.50 \pm 3.36$ & $102 \pm 7.67$ \\
\hline Final body weight (g) & $274.2 \pm 8.83$ & $289.42 \pm 10.54$ & $271.14 \pm 7.62$ & $275.16 \pm 6.96$ & $271 \pm 5.83$ \\
\hline Relative liver weight (g) & $2.42 \pm 0.08$ & $2.53 \pm 0.08$ & $2.54 \pm 0.07$ & $2.85 \pm 0.04^{\mathrm{a}}$ & $2.7 \pm 0.06^{\mathrm{a}, \mathrm{c}}$ \\
\hline Relative heart weight (g) & $0.33 \pm 0.01$ & $0.35 \pm 0.02$ & $0.40 \pm 0.01$ & $0.36 \pm 0.01$ & $0.40 \pm 0.01$ \\
\hline $\begin{array}{l}\text { Relative intra-abdominal } \\
\text { adipose tissue weight (g) }\end{array}$ & $1.54 \pm 0.09$ & $1.83 \pm 0.17$ & $1.50 \pm 0.14$ & $2.04 \pm 0.06^{\mathrm{a}, \mathrm{b}}$ & $2.58 \pm 0.17^{\mathrm{a}, \mathrm{c}}$ \\
\hline $\begin{array}{l}\text { Each value is expressed as mea } \\
\text { followed by Turkey post-hoc te } \\
\text { abdominal adipose tissue wei } \\
\text { Significantly different from co } \\
\text { group). }\end{array}$ & lled group. & ficantly diffe & $\mathrm{m}$ Ms & e data were $\mathrm{c}$ & $\begin{array}{l}\text { ed by ANOVA } \\
\text { Relative intra- } \\
\text { dy weight. ( a } \\
\text { erent from MP }\end{array}$ \\
\hline
\end{tabular}

Table 2: Effect of diets on fasting glycemia during experimentation.

\begin{tabular}{cccccc}
\hline & \multicolumn{5}{c}{ Blood glucose levels (mg/dl) } \\
\cline { 2 - 6 } Groups & $\mathbf{1}^{\text {st }}$ day & $\mathbf{1 5}^{\text {th }}$ day & $\mathbf{3 0}^{\text {th }}$ day & $\mathbf{4 5}^{\text {th }}$ day & $\mathbf{6 0}^{\text {th }}$ day \\
\hline Control & $67.40 \pm 0.97$ & $60.40 \pm 1.24$ & $65.20 \pm 2.97$ & $63.00 \pm 1.00$ & $64.20 \pm 2.20$ \\
MSG & $71.14 \pm 1.76$ & $67.1 \pm 2.00$ & $68.00 \pm 2.32$ & $66.57 \pm 2.18$ & $67.00 \pm 1.5$ \\
MP & $69.28 \pm 1.68$ & $64.85 \pm 1.53$ & $63.42 \pm 2.33$ & $64.42 \pm 2.42$ & $65.00 \pm 1.48$ \\
MSG-HF & $69.00 \pm 1.75$ & $79.40 \pm 0.60^{\mathrm{a}, \mathrm{b}}$ & $76.40 \pm 1.80^{\mathrm{a}, \mathrm{b}}$ & $75.66 \pm 2.87^{\mathrm{a}, \mathrm{b}}$ & $80.16 \pm 2.8^{\mathrm{a}, \mathrm{b}}$ \\
MP-HF & $72.14 \pm 1.98$ & $72.85 \pm 2.26^{\mathrm{a}, \mathrm{c}}$ & $76.40 \pm 1.88^{\mathrm{a}, \mathrm{c}}$ & $78.00 \pm 2.6^{\mathrm{a}, \mathrm{c}}$ & $78.28 \pm 1.4^{\mathrm{a}, \mathrm{c}}$ \\
\hline Blood glucose concentration was taken from conscious fasting rat at tail vein. Each value is expressed as mean \pm \\
standard error mean for seven rats per dietary group. The data were evaluated by ANOVA followed by Turkey post-hoc \\
test at 5\%. ${ }^{\text {a }}$ Significantly different from control group, ${ }^{\mathrm{b}}$ significantly different from MSG group, ${ }^{\circ}$ significantly different \\
from MP group.
\end{tabular}


Table 3: Blood glucose rates after 60 days treatment on fasting conditions and 30, 60, $120 \mathrm{~min}$ after oral glucose intake.

\begin{tabular}{lccccc}
\hline & \multicolumn{5}{c}{ Groups } \\
\cline { 2 - 5 } Parameters & Control & MSG & MP & MSG-HF & MP-HF \\
\hline $\begin{array}{l}\text { Fasting glycemia } \\
\text { (mg/dl) }\end{array}$ & $66.20 \pm 1.93$ & $67.28 \pm 1.52$ & $65.00 \pm 1.48$ & $80.14 \pm 2.43^{\mathrm{a}, \mathrm{b}}$ & $79.00 \pm 1.21^{\mathrm{a}, \mathrm{c}}$ \\
\hline $\begin{array}{l}\text { Glycemia 30 min } \\
\text { after glucose intake } \\
\text { (mg/dl) }\end{array}$ & $113.00 \pm 6.39$ & $117.42 \pm 3.81$ & $107.57 \pm 2.14$ & $135.85 \pm 7.97^{\mathrm{a}}$ & $120.85 \pm 1.54$ \\
\hline $\begin{array}{l}\text { Glycemia } 60 \text { min } \\
\text { after glucose intake } \\
\text { (mg/dl) }\end{array}$ & $111.80 \pm 6.32$ & $112.57 \pm 5.91$ & $120.57 \pm 4.70$ & $134.16 \pm 4.49^{\mathrm{a}, \mathrm{b}}$ & $107.00 \pm 1.55$ \\
\hline $\begin{array}{l}\text { Glycemia 120 min } \\
\text { after glucose intake } \\
(\mathrm{mg} / \mathrm{dl})\end{array}$ & $70.00 \pm 3.54$ & $93.71 \pm 3.86^{\mathrm{a}}$ & $83.85 \pm 4.61$ & $99.85 \pm 3.35^{\mathrm{a}}$ & $94.28 \pm 5.87^{\mathrm{a}}$ \\
\hline $\begin{array}{l}\text { Area under curve } \\
\text { (mg x min/ dl) }\end{array}$ & $11514 \pm 370.6$ & $12409.2 \pm 418.1$ & $12143.5 \pm 334.8$ & $14185.7 \pm 488.6^{\mathrm{a}}$ & $12454.2 \pm 228.7$ \\
\hline
\end{tabular}

Eighty per cent glucose solution was directly introduced by gavage into the stomach of fasted rat at a dose of $4 \mathrm{~g} / \mathrm{kg} \mathrm{b}$. wt. Blood glucose concentration was taken on conscious rat at tail vein using One Touch Ultra Two Glucometer before, 30, 60, $120 \mathrm{~min}$ after glucose load. Each value is expressed as mean \pm standard error mean for seven rats per dietary group. The data were evaluated by ANOVA followed by Turkey post-hoc test at $5 \%$. ${ }^{\text {a }}$ Significantly different from controlled group, ${ }^{\text {b }}$ significantly different from MSG group, ${ }^{\mathrm{c}}$ significantly different from MP group.

Table 4: Effect of diets on lipid profile and hepatic oxidative stress after 60 days supplementation.

\begin{tabular}{lccccc}
\hline & \multicolumn{5}{c}{ Groups } \\
\cline { 2 - 6 } Parameters & Control & MSG & MP & MSG-HF & MP-HF \\
\hline Total cholesterol $(\mathrm{g} / \mathrm{l})$ & $0.67 \pm 0.06$ & $0.68 \pm 0.06$ & $0.67 \pm 0.02$ & $0.63 \pm 0.03$ & $0.75 \pm 0.05$ \\
Triglycerides $(\mathrm{g} / \mathrm{l})$ & $0.44 \pm 0.02$ & $0.45 \pm 0.04$ & $0.42 \pm 0.02$ & $0.43 \pm 0.02$ & $0.52 \pm 0.02$ \\
HDL cholesterol $(\mathrm{g} / \mathrm{l})$ & $0.46 \pm 0.02$ & $0.41 \pm 0.05$ & $0.51 \pm 0.03$ & $0.47 \pm 0.03$ & $0.52 \pm 0.02$ \\
LDL cholesterol $(\mathrm{g} / \mathrm{l})$ & $0.11 \pm 0,05$ & $0.18 \pm 0.06$ & $0.19 \pm 0.13$ & $0.02 \pm 0.02$ & $0.17 \pm 0.03$ \\
$\begin{array}{l}\text { Malondialdehyde } \\
\text { (nmol/mg tissue) }\end{array}$ & $1.40 \pm 0.27$ & $2.98 \pm 0.52^{\mathrm{a}}$ & $2.62 \pm 0.16^{\mathrm{a}}$ & $2.97 \pm 0.08^{\mathrm{a}}$ & $2.88 \pm 0.12^{\mathrm{a}}$ \\
\end{tabular}

Total cholesterol, triglycerides and HDL cholesterol were assayed by enzymatic colorimetric method using Elitech/Biolabo kits. LDL cholesterol was estimated by Friedewal et al. (1972) empirical equation. Malondialdehyde concentration was estimated by thiobarbituric acid method (Bakoma et al., 2011). Each value is expressed as mean \pm standard error mean for seven rats per dietary group. The data were evaluated by ANOVA followed by Turkey post-hoc test at $5 \%$. ${ }^{\text {a }}$ Significantly different from controlled group. 


\section{DISCUSSION}

Monosodium glutamate is a worldwide used flavour enhancer with a level of consumption that has increased during the last two decades (Insawang et al., 2012). It can be used as purified glutamate salt or as a component of a mixture of amino acids and small peptides commonly called bouillon cube. This study was performed to analyse the effects of oral dose of purified MSG and MP (a bouillon cube containing 13\% of MSG) supplementation in combination or not with high fat on weight gain, body fat, lipid profile, glycemia and hepatic lipid peroxidation in Sprague Dawley rat. From our viewpoint, this is the first study that analyses systemic and morphological effects of MP compared to purified MSG ingestion in rat. We tested in sub-chronic conditions (60 days) a supranutritional dose of $1500 \mathrm{mg}$ of MSG or MP per kilogramme body weight in growing Sprague Dawley rat.

As expected, MSG or MP sub-chronic supplementation had no effect on body weight, gain, liver weight, heart weight and abdominal fat deposition. Our results are in accordance with those of Tordoff et al. (2012) who reported that $3 \%$ MSG in diet or in drinking water did not influence body weight and body fat store in three different species of rodents (Sprague Dawley rat, Obesity-prone Sprague Dawley derivated rat and C57BLI6J mouse) These findings are also in line with previous data from Boutry et al. (2011) who used a similar dose of $1295 \mathrm{mg} \mathrm{MSG/} \mathrm{kg} \mathrm{b.} \mathrm{wt}$ in diet or drinking water of Wistar rat. However, it has been suggested in several animal studies that MSG is able to induce overweight or obesity. In these MSG-induced obesity rat models; MSG is injected subcutaneously to newborn rats or administered by oral route at higher doses (5000 mg MSG/day) to young rats (Hermanussen et al., 2006). The induction of obesity in animals treated in this manner required that plasma GLU concentrations be elevated to very high values, sufficient enough to penetrate into the brain and exert deleterious effects on the arcuate nucleus neurons. Plasma hyperglutamataemia thereby, can disrupt the hypothalamic signaling cascade of leptin action and cause hyperphagia and obesity (Diniz et al., 2005; Kondoh and Torii 2008; Boutry et al., 2011). In our conditions, since rats did not manifest deleterious effects of overweight and obesity; it seems therefore that GLU derived from MP or MSG ingested is almost entirely (up to $95 \%$ ) catabolised by the enterocyte of intestinal mucosa (Beyreuther et al., 2007).

The combination of MSG and high fat or MP and high fat feeding resulted in an increase of relative liver weight and abdominal fat deposition. This result is not unexpected as far as lard-based diets induced hepatic steatosis and are recommended as one of the standard fats to be used for the generation of a valid rat model for the metabolic changes associated with obesity (Buettner et al., 2006)

The present work demonstrates that both MSG and MP sub-chronic ingestion in Sprague Dawley rat did not increase fasting glycemia during the supplementation. However, the oral glucose challenge generated a normal blood glucose response in MP rats whereas a hyperglycemic response was observed in MSG rats. In this way, MP fed rats' plasma glucose concentration declines to near baseline values at $120 \mathrm{~min}$ after load while it remained significantly higher in MSG fed Sprague Dawley rat. These results highlight the reduction of glucose utilisation by peripheral tissues in postprandial conditions in MSG fed rats. Elevated plasma glutamate is well known to enhance insulin secretion which can lead to hyperinsulinemia and insulin resistance in sub-chronic conditions (Chevassus et al., 2002). The low amount of MSG contained in the MP diet may explain the relative normal glucose homeostasis observed in this group. In MSG$\mathrm{HF}$ and MP-HF diet groups; lard has exacerbated glucose intolerance by increasing 
fasting glucose levels and glucose AUC during the OGTT. Huang et al. (2004) pointed out in their report that prolonged high fat diet supplementation can cause abnormality of the pancreas function and impaired insulin secretion. However, the alteration of glucose homeostasis in all experimental rats is not elevated to such point to be considered as prediabetic animals while basing esclusively on glucose criteria (Buysschaert and Bergam, 2011).

Serum lipids were all within the normal range and did not differ into the five groups whereas hepatic lipid peroxidation (MDA) had increased in all experimental groups. Such findings indicate that MSG and MP oral ingestion do not cause dyslipidemia but induce oxidative stress in Sprague Dawley rat. Kondoh and Torii (2008) also observed that the voluntary ingestion of $1 \%$ MSG solution had no effect on lipid profile in Sprague Dawley rat. However, lipid profile in MSG fed rats is very different from data obtained by Singh et al. (2011) who reported that the oral ingestion of MSG at dose level of 4 and $8 \mathrm{mg} /$ b. wt. signifanctly increased the level of serum lipid by $19.93 \%$ and $29.37 \%$ in male Wistar rat during 7 days supplementation. They suggest that glutamate favours lipogenesis by converting to glutamine. This hypothesis is confirmed by Boutry et al. (2011), who demonstrated that after 15 days of 2\% MSG dietary adaptation in Wistar rat, the circulating glutamine concentration has increased. We suggest therefore that Wistar rat could be more sensitive to the effects of MSG than Sprague Dawley rat. On the other hand, Egbuonu et al. (2009) found that oral intake of low dose of MSG (5 mg/b. wt.) by gastric tube in Wistar rat may be destructive to the liver. The mechanism involved in the production of hepatic MDA may be the generation of reactive oxygen species by MSG which is also an endogenous excitotoxin (Ortiz et al., 2006; Eweka and Om'lniabohs 2011).

\section{Conclusion}

To sum up, this study shows that subchronic MP or MSG administration (60 days) at a dose of $1500 \mathrm{mg} / \mathrm{b} . w \mathrm{w}$. does not impair glucose tolerance but it promotes hepatic lipid peroxidation in male Sprague Dawley rat. A combination of MSG and high fat or MP and high fat supplementation in Sprague Dawley rat during growth may predispose to a glucose homeostasis impairment. The findings of this work are supplemental data confirming earlier reports on the hepatotoxicity and the potential role of MSG in the increasing prevalence of prediabetes and metabolic syndrome in human being. Further investigations using long term supplementation of MSG at various doses in rats and humans are needed to raise the ambiguity.

\section{ACKNOWLEDGEMENTS}

This study was partially supported by the Faculty of Sciences of the University of Lomé, Togo.

\section{REFERENCES}

Akpamu U, Nwaopara AO, Izunya AM, Oaikhena GA, Okhiai O, Idonije BO, Osifo UC. 2011. A comparative study on weight changes in rats fed with diet containing Yaji, Yaji-additives and Yaji-spices. Biol. Med., 3(5): 06-15.

Bakoma B, Eklu-Gadegbeku K, Agbonon A, Aklikokou A, Bassene E, Gbeassor M. 2011. Preventive effect of Bridelia ferruginea against high-fructose induced glucose intolerance, oxidative stress and hyperlipidemia in male Wistar rat. $J$. Pharmacol Toxicol., 6(3): 249-257.

Beyreuther K, Biesalski HK, Fernstrom JD, Grimm P, Hammes WP, Heinemann U, Kempeski O, Stehle $\mathrm{P}$, Steinhart $\mathrm{H}$, Walker R. 2007. Consensus meeting: monosodium glutamate - an up date. Eur. J. Clin. Nutr., 61: 304-313.

Boutry C, Bos C, Matsumoto H, Even P, Azzout-Marniche D, Tomé D, Blachier F. 2011. Effects of monosodium glutamate 
supplementation on glutamine metabolism in adult rats. Frontiers Biosci., 1(3): 27990.

Brohall G, Behre CJ, Hulthe J, Wikstrand J, Fagerberg B. 2006. Prevalence of diabetes and impaired glucose tolerance in 64year-old Swedish women: experiences of using repeated oral glucose tolerance tests. Diabet. Care, 29: 363367.

Buettner R, Parhofer KG, Woenckhaus M, Wrede CE, Kunz-Schughart LA, Schölmerich J, Bollheimer LC. 2006. Defining high-fat-diet rat models: metabolic and molecular effects of different fat types. J. Mol. Endocrinol., 36: 485-501.

Buysschaert M, Bergam M. 2011. Definitions of prediabetes. Med. Clin. N. Am., 95: 289-297.

Chevassus H, Renard E, Bertrand G, Mourand I, Puech R, Molinier N, Bockaert J, Petit P, Bringer J. 2002. Effects of oral monosodium (L)-glutamate on insulin secretion and glucose tolerance in healthy volunteers. $\mathrm{Br} . \mathrm{J} . \mathrm{Clin}$. Pharmacol., 53(6): 641-643.

Collison KS, Maqbool ZM, Inglis AL, Makhoul NJ, Saleh SM, Bakheet RH, AlJohi MA, Zaidi R, Al-Mohanna F. 2010. Effect of dietary monosodium glutamate on HFCS- induced hepatic steatosis: expression profiles in the liver and visceral fat. Obes., 18: 1122-113.

David MN, Mayer BD, Ralph AD, Robert JH, Robert RH, Richard P, Bernard Z. 2007. Impaired fasting glucose and impaired glucose tolerance: implications for care. Diabet. Care, 30(3): 753-759.

Diniz SY, Fernandes AH, Campos KE, Mani F, Ribas BO, Novelli EL. 2004. Toxicity of hypercaloric diet and monosodium glutamate: oxidative stress and metabolic shifting in hepatic tissue. Food Chem. Toxicol., 42: 313-319.

Diniz SY, Faine LA, Galardhi CM, Rodrigues HG, Ebaid GX, Burneiko RC, Cicogna
AC, Novelli EL. 2005. Monosodium glutamate in standard and high-fiber diets: metabolic syndrome and oxidative stress in rats. Nutr., 21: 749-755.

Egbuonu AC, Obidoa O, Ezeokonkwo CA, Ezeanyika LU, Ejikeme PM. 2009. Hepatotoxic effects of low dose oral administration of monosodium glutamate in male albino rats. Afr. J. Biotechnol., 8(13): 3031-3035.

Eweka AO, Om'lniabohs FA. 2011. Histochemical studies of the effects of monosodium glutamate on the liver of wistar rats.. Annals Med. Health Sci. Res., 1: 21-29.

Frieldewald WT, Levy RS, Friedricksen DS. 1972. Estimation of concentration of low density lipoprotein cholesterol in plasma without rise of preparative ultracentrifuge. Clin. Chem., 18: 499-502.

Hermanussen M, Garcia AP, Sunder M, Voigt M, Salazar V, Tresguerres JA. 2006. Obesity, voracity, and short stature: the impact of glutamate on the regulation of appetite. Eur. J. Clin. Nutr., 60(1): 25-31.

Huang BW, Chiang MT, Yao HT, Chiang W. 2004. The effect of high-fat and fructose diets on glucose tolerance and plasma lipid and leptin levels in rats. Diabet. Obes. Metabol., 6: 120-126.

Insawang T, Selmi C, Cha' on U, Pethlert S, Yongvanit P, Areejitranusorn P, Boonsiri $\mathrm{P}$, Khampitak T, Tangrassameeprasert R, Pinitsoontorn C, Prasongwattana V, Gershwin ME, Hammock BD. 2012. Monosodium glutamate (MSG) intake is associated with the prevalence of metabolic syndrome in a rural Thai population. Nutr. Metab., 9(50): 1-6.

Kondoh T, Torii K. 2008. MSG intake suppresses weight gain, fat deposition, and plasma leptin levels in male Sprague-Dawley rats. Physiol. Behav., 95(1-2): 135-144.

Ortiz GG, Bitzer-Quintero OK, Zárate CB, Rodrigues-Reynoso S, Larios-Arceo F,Velazquez-Brizuela IE, Pacheco- 
Moisés F, Rosales-Corral SA. 2006. Monosodium glutamate induced damage in liver and kidney; a morphological and biochemical approach. Biomed. Pharmacother., 50: 86-91.

Sepici-Dincel A, Ereften S, Cemal C, Sengelec M, Yesiladad E. 2007. Effet of in vitro anti- oxydant enzyme activities in myrtyle oil in normoglycemic and alloxan diabetic rabbit. J. Ethnopharmacol., 110: 498-503.

Singh K, Sharma J, Kaur A, Ahluwalia P. 2011. Alteration upon oral ingestion of monosodium glutamate in various lipid and lipoprotein fractions in serum in adult male rat. J. Life Sci. 3(1): 17-21.
Sop KM, Fotso M, Gouado I, Tetanye E, Amvam Zollo PH. 2008. Nutritional survey, staple foods composition and the uses of savoury condiments in Douala, Cameroon. Afr. J. Biotechnol., 7(9): 13391343.

Tordoff MG, Aleman TR, Murphy MC. 2012. No effects of monosodium glutamate consumption on the body weight or composition of adult rats and mice. Physiol. Behav., 107: 338-345.

Von Diemen V, Trindade EN, Trindade MR. 2006. Experimental model to induce obesity in rats. Acta. Cir. Bras., 21: 425442. 